LBNL-47382

\title{
Evaluation of flow hood measurements for residential register flows
}

\section{Walker, I.S., Wray, C.P., Dickerhoff, D.J.,}

\section{and Sherman, M.H.}

Energy Performance of Buildings Group

Lawrence Berkeley National Laboratory

One Cyclotron Road

Berkeley, CA 94720

This work was supported by the California Institute for Energy Efficiency, a research unit of the University of California, under Contract No. S9902A through the U.S. Department of Energy under Contract No. DE-AC03-76SF00098. 


\section{Table of Contents}

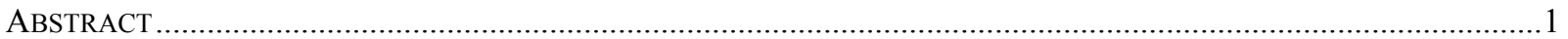

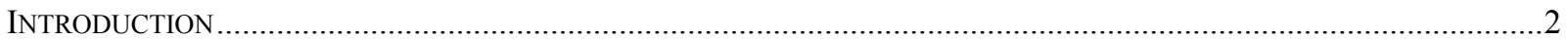

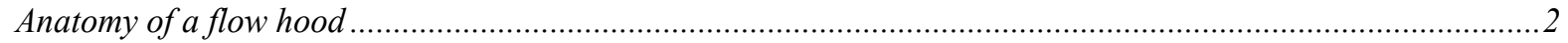

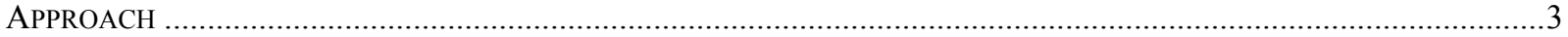

Table 1. Summary of accuracy criteria for register flow measurement applications ............................................... 4

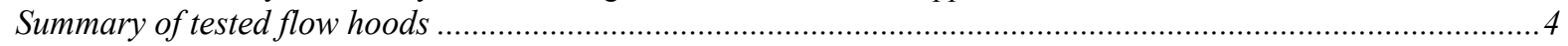

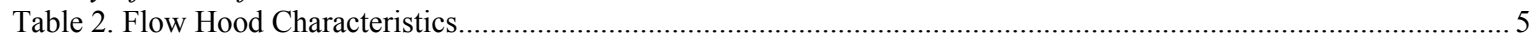

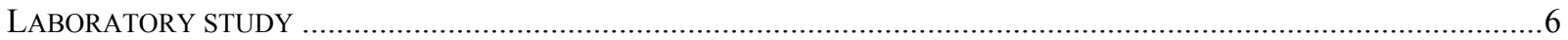

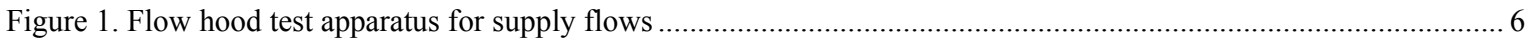

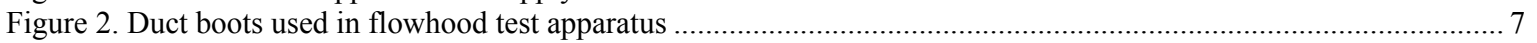

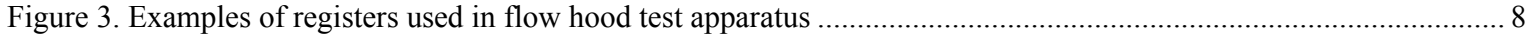

Figure 4: Three flow capture hood positions relative to the register grille ......................................................... 8

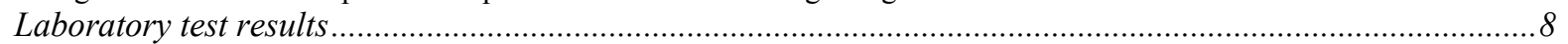

Table 3. Summary of Laboratory Test Results for Supply and Return Flows..................................................... 9

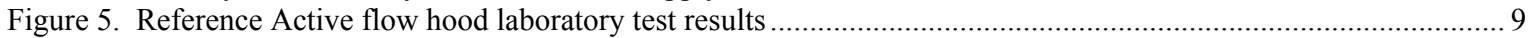

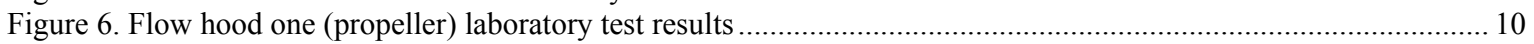

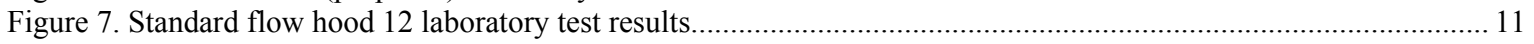

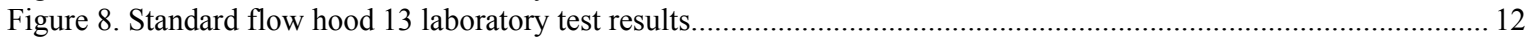

Figure 9. Prototype Hood 11 Laboratory Test Results for Supply Airflows ........................................................ 12

Figure 10. Laboratory Test Results for High Supply and Return Airflows Measured with Reference Active Flow Hood 13

Figure 11. Laboratory Test Results for Supply and Return Airflows Measured with Prototype Flow Hood 11 .............. 14

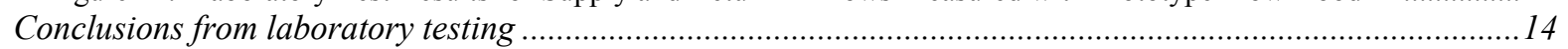

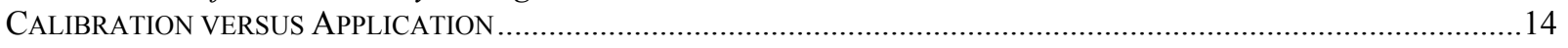

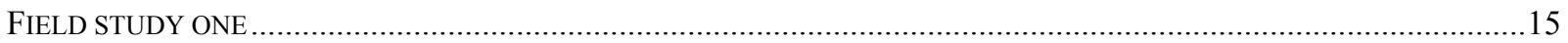

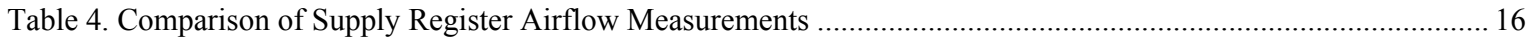

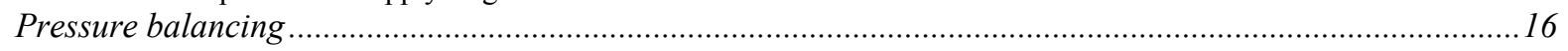

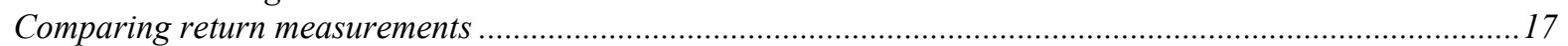

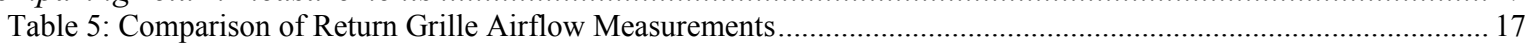

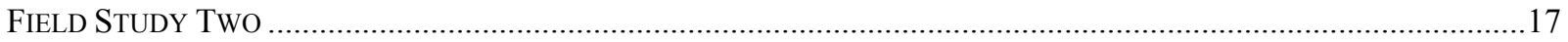

Figure 12. Results of a field test comparison between prototype Flow Hood 11 and the Reference active flow hood for

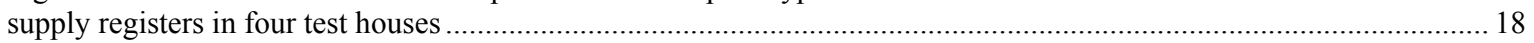

Table 6: Comparison of 6 Return Grille Airflows Measured in Four Houses using the Reference Active Flow Hood and

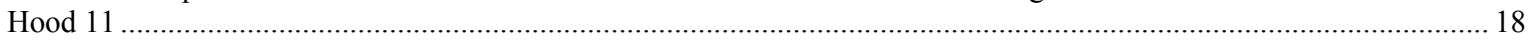

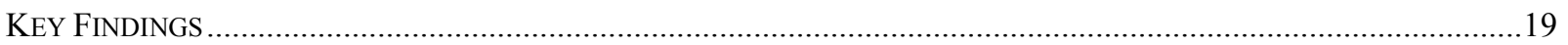

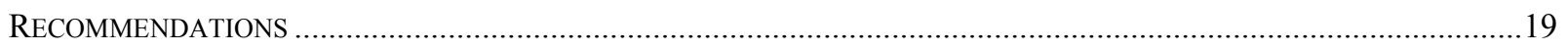

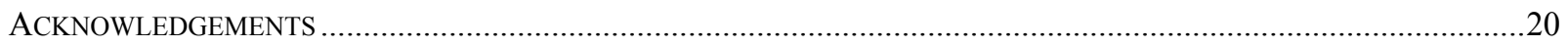

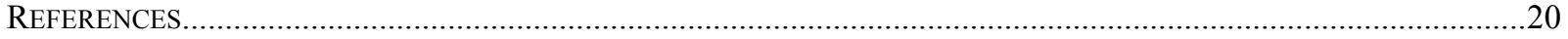




\section{Abstract}

Flow measurement at residential registers using flow hoods is becoming more common. These measurements are used to determine if the HVAC system is providing adequate comfort, appropriate flow over heat exchangers and in estimates of system energy losses. These HVAC system performance metrics are determined by using register measurements to find out if individual rooms are getting the correct airflow, and in estimates of total air handler flow and duct air leakage. The work discussed in this paper shows that commercially available flow hoods are poor at measuring flows in residential systems. There is also evidence in this and other studies that flow hoods can have significant errors even when used on the non-residential systems they were originally developed for. The measurement uncertainties arise from poor calibrations and the sensitivity of exiting flow hoods to non-uniformity of flows entering the device. The errors are usually large - on the order of $20 \%$ of measured flow, which is unacceptably high for most applications. Active flow hoods that have flow measurement devices that are insensitive to the entering airflow pattern were found to be clearly superior to commercially available flow hoods. In addition, it is clear that current calibration procedures for flow hoods may not take into account any field application problems and a new flow hood measurement standard should be developed to address this issue. 


\section{Introduction}

The purpose of this report is to evaluate methods for determining the flow through residential registers as it relates to the testing and balancing industry. Although specific flow hoods were tested by LBNL, the focus of this report is on the behavior of product classes and not on specific products. Conclusions and recommendations in this report should not be considered as criticism or endorsements of any specific product.

Flow hoods have been used for many years in the HVAC industry as a method of measuring the air flows at registers. Until recently, almost all register measurements were made in non-residential buildings, usually as part of a testing and balancing procedure for the HVAC system. Most commercially available flow hoods were developed for use on non-residential systems with the register sizes and flow rates common to these systems. Residential HVAC systems were very rarely tested in the past; however, utility programs, weatherization programs, and codes and standards developments (that require commissioning of residential HVAC systems) are beginning to look at this important aspect of residential HVAC system performance. The register flows in residential systems are used to determine if individual rooms are getting the correct airflow, and in estimates of total air handler flow and duct air leakage.

There have been a few previous studies that looked at flow hoods used in commercial applications (Choat 1999) that found flow hoods to be poor at measuring register flows, but no published studies on residential flow hood uncertainties.

Measuring residential register flows represents a challenge for a flow hood developed for commercial systems for the following key reasons:

- The flows at an individual residential register are typically much lower than for non-residential systems. Usually, they are in the range of 25 to $75 \mathrm{l} / \mathrm{s}$ (50 to $150 \mathrm{cfm}$ ), with some flows substantially lower than this (e.g., small interior bathrooms often have design flows in the $51 / \mathrm{s}(10 \mathrm{cfm})$ range). For comparison, commercial systems typically have flows in excess of $120 \mathrm{l} / \mathrm{s}(250 \mathrm{cfm})$. Many commercially available flow hoods claim to be able to measure these lower flows.

- Residential registers are often physically smaller than commercial systems. A typical residential register is 150 $\mathrm{mm} \times 300 \mathrm{~mm}(6 \times 12$ inches $)$ rather than $560 \mathrm{~mm}(22$ inches) square (This is the actual size, commercial registers are nominally $24 \times 24$ inches). This introduces errors due to the flow being non-uniform over the inlet of the flow hood. Some residential systems have single return registers that are closer to commercial registers in terms of size and air flow; however, they often have dimensions larger than the $560 \mathrm{~mm}$ (22 inch) square standard flow hood. In these cases it necessary to make several individual measurements over the face of the register and then combine these multiple measurements. There are substantial potential errors with this measurement technique, e.g., the flow into the register bypassing the flow hood if it only covers part of the register.

- Residential registers do not have diffusers (that make the flow spatially homogeneous) - instead they tend to have vanes that direct the flow in a particular direction. These leads to highly non-uniform flows entering the flowhood. In some cases these directed flows are part of the system design in which the throw of air from the register into the room is important.

- Insertion losses. Many residential systems have branches close to registers. This makes the flow out of the register being measured sensitive to the backpressure/flow resistance of the measurement device. The added flow resistance of the measurement device significantly increases the flow resistance of the branch being measured and therefore too low a flow is measured (the rest of the flow goes out through the neighboring register).

\section{Anatomy of a flow hood}

The basic design of flow hoods comprise of a flow capture device and a measurement device. The flow capture device is usually a fabric hood mounted over a rigid frame (often collapsible for storage and transportation) that directs the air flow over a sensing element (or elements) in the measurement device. The hood has a larger open end that is usually sized to fit a standard commercial register of $560 \mathrm{~mm} \times 560 \mathrm{~mm}(22 \times 22$ inches $)$ with other hood sizes offered by many manufacturers. Flow measurement techniques differ between manufacturers and include pressure drop, hot wire, plate deflection, spinning propellers etc. Most flow hoods can measure flows in either direction (for supply and return registers) and they have the capability to perform time averaging. In addition they have multiple 
flow ranges that usually are achieved by changing the readout device. Some flow hoods have a system of user operable openings and flaps that reduce backpressures at higher flows.

\section{Approach}

In order to determine the magnitude of errors associated with the application of flow hoods to measuring the flows at residential registers, a detailed laboratory test and two field studies were undertaken. The laboratory tests allow the systematic variation of potential sources of uncertainty where the flow hoods can be compared to a very accurate "truth" standard. The field studies illustrate how the uncertainties revealed by the laboratory tests affect field measurements. In both the laboratory and field studies, several commercially available flow hoods were used together with some state-of-the-art active flow hoods.

Flow hoods have several applications that may require different levels of accuracy in order to be acceptable. In order to evaluate the performance of the tested flow hoods, acceptable performance criteria need to be established. The applications can be split into two subsets:

Subset 1: Individual register flows. These measurements are used to determine if enough heating or cooling is delivered by a register to the space it serves, to determine flow imbalance between different spaces in a building, and to identify parts of a system with large leaks (e.g., disconnected ducts). For identifying large leaks or disconnected ducts, the airflow changes are large and the accuracy of the measurement is not critical and being within $\pm 50 \%$ of the correct flow is reasonable. Similarly, imbalances in flows are only critical in residences at higher flow rates and an accuracy of $\pm 25 \%$ is probably reasonable. The performance criterion for this subset is limited by the requirement to provide enough heating or cooling airflow. The required accuracy of the measurement can be based on estimating the room temperature variation based on the change in air flow. Consider a register flow sized at winter design conditions in Minneapolis, MN. With a desired indoor temperature of $20^{\circ} \mathrm{C}$ and an outdoor design condition of $24^{\circ} \mathrm{C}\left(99 \%\right.$ design condition from ASHRAE Fundamentals 1997) the temperature difference is $44^{\circ} \mathrm{C}$. The register flow is then set to meet the envelope load created by this temperature difference. Reasonable limits on the room temperature would be $\pm 2^{\circ} \mathrm{C}$. Because the delivered heat scales with the register air flow, the ratio of the acceptable range for temperature changes to the total temperature difference is the same the acceptable range of register flows. In this case the range is $\pm 2 / 44$ or $\pm 4.5 \%$. This means that a change in register flow of only $5 \%$ would make the room too hot or too cold. It is reasonable to require that the measurements of register flows can at least meet this $\pm 5 \%$ limit for accuracy if the register measurements are being used to determine occupant comfort. In less harsh climates where individual room loads are smaller, the range of register flows for acceptable comfort will be wider. For example, in Fresno, CA the outdoor design temperature is $0^{\circ} \mathrm{C}$. This effectively doubles the acceptable range of register flows that would provide the same $\pm 2^{\circ} \mathrm{C}$ room temperature, and the flow hood accuracy could be expanded to $\pm 10 \%$. However, a climate based accuracy specification for flow hoods would be extremely unwieldy and the specification used in this report will be based on the $\pm 5 \%$ limit for high load conditions.

Subset 2: Total of all register flows. In this case, all the individual register measurements are summed to find the total supply or return air flow. This total flow can be used to estimate supply/return imbalances, air handler flow (if leakage is well known), and duct leakage quantification (if air handler flow and leak location are well known). The key uses in residential systems are the air handler flow and leakage determination because residences are generally not designed to be deliberately pressurized or depressurized (although this measurement might be useful in some situations, e.g., determining the degree of house depressurization in backdrafting investigations). For air handler flows, the desire to have the correct air handler flow is most critical for cooling systems whose capacity and efficiency are reduced at lower air handler flows. The effects of air handler flow become significant if air handler flows are about 15\% lower than desired (An 8\% reduction in equipment efficiency was found by Rodriguez et al. (1995) for flow reduction of 15\%). If the register measurements are to be used to estimate the effect of air handler flow on equipment performance and a reasonable limit for changing the equipment performance is about $5 \%$ then the total of all register flows needs to have an accuracy better than about $\pm 10 \%$. The requirements are more restrictive for using the results to calculate duct leakage. The current low leakage limits set by various authorities for duct leakage are between 6\% (CEC 1998) and 10\% (State of Oregon and proposed EPA EnergyStar ducts) for the whole duct system. Because this includes both supply and return leaks and the register flow measurement technique measured the supply and return separately, this technique is being used to determine flows on the order of 
$3 \%$ to $5 \%$ of air handler flow. If duct leakage testing needs to verify these low leakage levels or provide reasonable estimates of the energy penalty of leakier ducts, then the duct leakage measurement accuracy needs to be better than $\pm 3 \%$. Assuming there is no uncertainty in the air handler flow measurement, this implies that the total of all register flows needs to have an accuracy better than $\pm 3 \%$. Note that this is implies an uncertainty almost the same as the measurement when verifying low leakage ducts and it would be preferable to have a much tighter specification here of about $\pm 1 \%$ of air handler flow. In addition, this does not address the uncertainty in air handler flow measurement or estimating what fraction of the total leakage (the difference between air handler and register flow) is to outside (as required for energy loss calculations).

\begin{tabular}{|l|c|}
\hline \multicolumn{2}{|l|}{ Table 1. Summary of accuracy criteria for register flow measurement applications } \\
\hline Application & Required Minimum Accuracy \\
\hline Identifying Large leaks/disconnected ducts & $\pm 50 \%$ \\
\hline Identifying room to room pressure imbalances & $\pm 25 \%$ \\
\hline Ensuring room load and comfort requirements are met & $\pm 5 \%$ \\
\hline Determining overall system flow imbalances & $\pm 10 \%$ \\
\hline $\begin{array}{l}\text { Determining air handler flow for cooling equipment } \\
\text { performance estimation }\end{array}$ & $\pm 10 \%$ \\
\hline Determining duct leakage & $\pm 3 \%$ \\
\hline
\end{tabular}

\section{Summary of tested flow hoods}

Flow hoods from major manufacturers were included in this study together with a couple of active flow hoods and a propeller flow hood no longer in production (but still in use with residential air flow practitioners).

The standard flowhoods use fabric hoods over a collapsible rigid frame that directs the flow over a velocity sensing element. These velocity sensing elements use thermo-anemometers and the pressure drop across the throat of the flow hood. The flow is sampled at several fixed locations within the throat of the flow hood - usually a couple of points each on four fixed radii. With fixed sampling locations it is possible that non-uniform flows will not be sampled with sufficient spatial resolution - or the correct weighting applied to each sample. Standard flow hoods from three manufacturers were used, in addition to a smaller flowhood developed by one manufacturer for use on smaller systems.

The propeller flowhood has a rigid glass fiber flow capture section and was specifically developed for the smaller registers and flow in residential systems. The flow sensing element is a freely spinning propeller that spins faster as the air flow increases. The speed of the propeller indicates the flow through the flow hood. A possible advantage of the propeller flow hood is that that it can sample the whole flow because all the flow must pass through the propeller (the propeller tip clearance to the rigid glass fiber housing is very small). However, it does not eliminate the problems of non-uniform flow completely due to inertial effects of the propeller and the non-linear interactions between local air flow velocity and the rotational force applied to the propeller. In addition, it is possible that swirl in the flow will cause the propeller to spin either too fast or too slow - thus biasing the measurements. This flow hood is no longer manufactured, but it is still used by some practitioners.

The active flow hood was originally developed to reduce the effects of back pressure on the flow measurement. Laboratory and field experience has shown that a more important attribute is the insensitivity to non-homogeneous register flows. Because the laboratory test results showed this flow hood to be very accurate, it was used as the reference flow hood for the field studies. The active flow hood is sometimes referred to as a fan assisted flow hood. The active flow hood uses a flow capture device from a standard commercially available flow hood. A calibrated fan-flowmeter device is connected to the outlet of the hood with a length of plastic flex duct and a flow straightener. The pressure sampling tube array already mounted in the throat of the flow hood is used in the system used in this study to measure the pressure inside the hood. An alternative is to use a cardboard box in place of the commercial flow capture device. The hood pressure can be measured by inserting a pressure tap into a corner of the box such that it is not in the main flow. The flow resistance of the capture hood, flexible duct and flowmeter is compensated for by adjusting the fan until there is no pressure difference between the room and the hood. This pressure balancing procedure ensures that the flow out of the register is not reduced by placing the flow hood over the register. These devices are not very sensitive to how this hood reference pressure is measured. Field measurements (discussed later) have shown that the differences in indicated flows are smaller then the manufacturer specified accuracy of the flow 
measurement device ( $\pm 3 \%$ of flow). This device is not commercially available as a complete package, however, many practitioners have the fan-flowmeter device used in these tests.

Non-standard flow hoods use different methods for flow capture and sensing. The specific type tested in this study uses a flow capture device like a standard flowhood, and a novel flow capture, sampling and sensing technology.

\begin{tabular}{|c|c|}
\hline \multicolumn{2}{|r|}{ Table 2. Flow Hood Characteristics } \\
\hline Hood & Characteristics \\
\hline 1 & Rigid fiberglass capture hood with propeller flow measurement (manufacturer A) \\
\hline 2 & Conventional flow hood with flow pressure averaging manifold (manufacturer B) \\
\hline 3 & $\begin{array}{l}\text { Conventional flow hood with flow pressure } \\
\text { specifically for low residential flows (manufacturer B) }\end{array}$ \\
\hline 4 & Conventional flow hood with flow pressure averaging manifold (manufacturer C) \\
\hline 5 & Conventional flow hood with flow pressure averaging manifold (manufacturer D) \\
\hline 6 & $\begin{array}{l}\begin{array}{l}\text { Conventional flow hood with flow pressure averaging } \\
\text { same as Hood 5, but different serial number) }\end{array} \\
\end{array}$ \\
\hline 7 & Reference Active flow hood using total hood pressure balance \\
\hline 8 & Active flow hood using static hood pressure balance \\
\hline 9 & $\begin{array}{l}\text { Active flow hood with same measurement device as the reference active hood, but uses cardboard } \\
\text { box capture hood with hood-corner pressure balance (manufacturer E) }\end{array}$ \\
\hline 10 & $\begin{array}{l}\text { Active flow hood with same measurement device as the reference active hood, but uses cardboard } \\
\text { box capture hood with near-fan-entry hood pressure balance (manufacturer E) }\end{array}$ \\
\hline 11 & Prototype flow hood with flow pressure averaging manifold (manufacturer F) \\
\hline 12 & $\begin{array}{l}\text { Conventional flow hood with flow pressure averaging manifold and tall hood, } \\
\text { specifically for low residential flows (manufacturer B) }\end{array}$ \\
\hline 13 & $\begin{array}{l}\text { Conventional flow hood with flow pressure averaging manifold and short hood, } \\
\text { specifically for low residential flows (manufacturer B) }\end{array}$ \\
\hline
\end{tabular}

A total of 13 flow hoods were evaluated in this study and they are summarized in Table 2. Two of the flow hoods were active flow hoods that used the flow hood as a flow capture device and measured the flow with a separate flowmeter. To test the sensitivity of the active flow hoods to the setting of the balancing pressure, the tests were repeated with different measurements of balancing pressure. The reference active flow hood was tested in two modes:

1. Balancing the flow hood approximation of total pressure with room static pressure. The flow hood approximation of total pressure was measured using the pressure sampling array in the throat of the hood that is normally used for direct flow hood measurements.

2. Balancing the room and flow hood static pressure, with flow hood static pressure measured in the corner of the flow hood up against the wall - i.e., as distant from the bulk flow field as possible.

The second active flow hood was also tested in two modes:

1. Balancing the flow hood and room static pressures, with static pressure measured in the corner of the flow capture hood near the wall

2. With the flow capture hood static pressure measured at the other end of the flow capture hood near the fan/flowmeter entrance. 
The other nine flow hoods were from six different manufacturers. Flow hood 1 is currently not commercially available, but was included because it is in use by field practitioners. Flow hood 11 is a prototype flow hood that is still under development and is also not generally available.

\section{Laboratory study}

Because field studies have large potential errors, a laboratory study was performed in which key parameters could be better controlled than in a field test. The laboratory tests evaluate the factory calibration and the sensitivity of the results to changes in the entering flow pattern (which can be thought of as the robustness of the measurement technique/device). The entering flow pattern was changed by adjusting hood placement over register, different grille styles, different damper settings and the boot type. The flow hoods tested in the laboratory were: the active flowhood (Flow Hood 7), the propeller flow hood (Flow Hood 1), the standard flow hood (Flow Hood 2), the small flow hood (Flow Hood 3), the prototype flow hood (Flow Hood 11).

The laboratory tests are of a "single branch" system in which all the flow through the reference nozzle passes through the flowmeter. Therefore the laboratory tests do not evaluate the effect of insertion losses, i.e. how placing the flowhood over the register changes the airflow through the register (and the rest of the system) by changing the flow resistance of the individual register branch. These insertion effects are currently being evaluated.

Figure 2 shows a schematic of the equipment used to evaluate airflow measurement accuracy of flow capture hoods for supply flows. For return flows the fan and flowmeter are reversed and the air flow direction was reversed. For the larger square registers the rectangular boot was replaced by a small cardboard plenum. All joints, ducts, plenums, and boots downstream from the flow meter were carefully sealed and tested under pressure to ensure that they did not leak. In addition to the supply register tests, Flow Hood 11 and the active flowhood were tested for their ability to measure return flows.

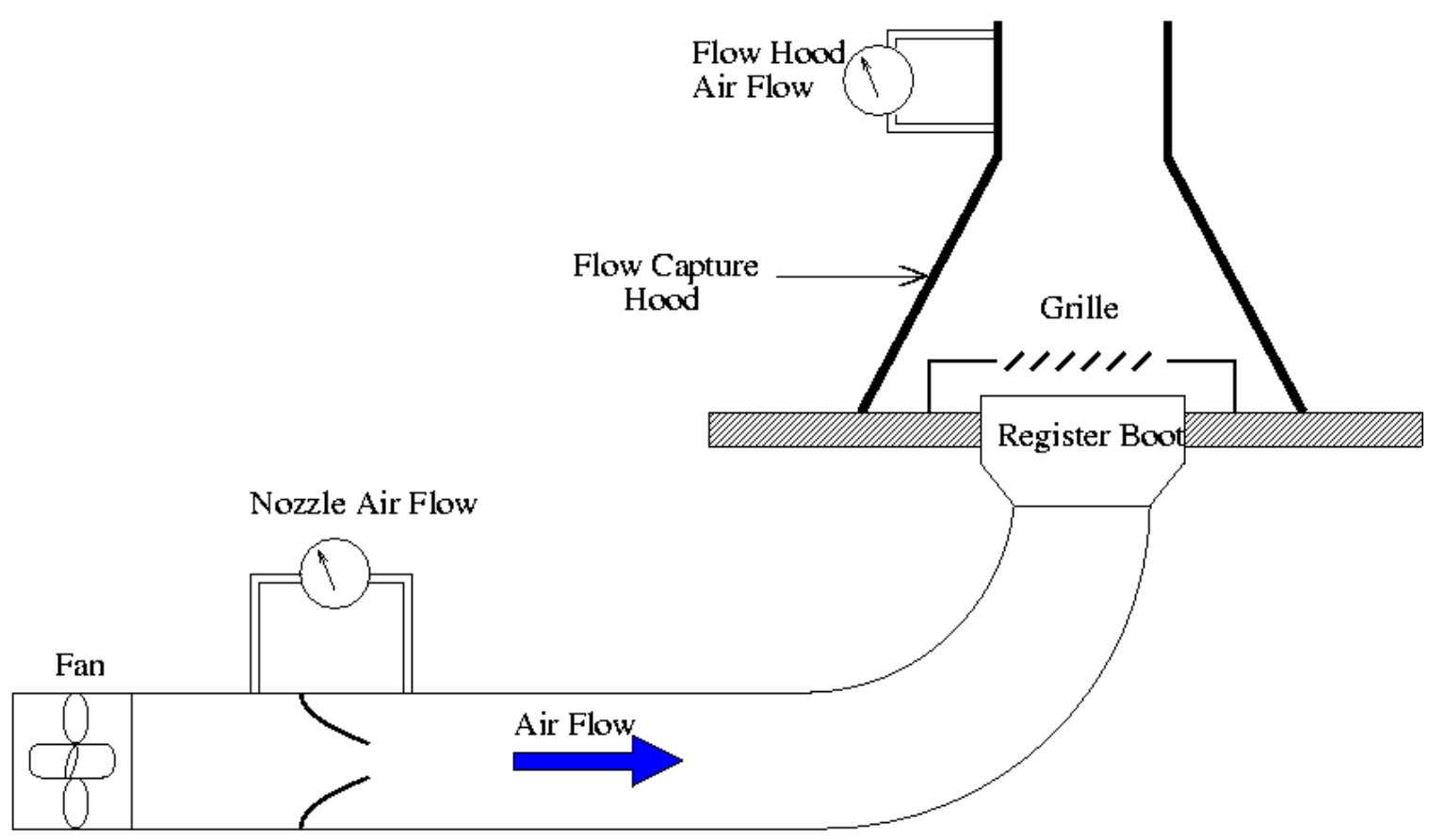

Flow Nozzle

Figure 1. Flow hood test apparatus for supply flows 
An adjustable fan was used to produce a range of flows through the test apparatus. The flows covered the range of typical residential register flows, i.e., 25 to $120 \mathrm{l} / \mathrm{s}(50$ to $250 \mathrm{cfm}$ ) for supplies and up to $1000 \mathrm{l} / \mathrm{s}$ ( $2000 \mathrm{cfm})$ for returns. The air flows were measured using a flow nozzle with an accuracy of $\pm 0.5 \%$ of the flow reading. This device combines a flow straightener, a nozzle, and a pitot-averaging-array to form a flow meter that is less sensitive to flow asymmetry than other flow meters. In order to maintain the measurement accuracy over the wide range of test conditions a nominal $150 \mathrm{~mm}(6 \mathrm{inch})$ diameter nozzle for flows of $120 \mathrm{l} / \mathrm{s}(250 \mathrm{cfm})$ or less and an $450 \mathrm{~mm}(18$ inch) diameter nozzle for larger flows were used. Upstream of the register boot there is about $2 \mathrm{~m}$ (6 feet) of 150 $\mathrm{mm}$ (6inch) diameter duct ( $0.7 \mathrm{~m}$ (two feet) of sheet metal and $1.3 \mathrm{~m}$ (four feet) of flexible aluminized plastic). The register boot was connected to a plywood sheet that represents the flat surface the register would be on in a real building. The register grille was then connected to the boot. The damper within the grille assembly was used in a couple of different settings. Some tests were also performed without the grille - just the open end of the duct. The flow hoods were placed over the grille such that the edge of the flowhood was pressed against the plywood surround.

Two rectangular boots were used on these tests. The boots had different entry conditions for the six inch duct: either from the side (Boot A) or from the end (Boot B). In addition, Boot A had a $100 \mathrm{~mm} \times 250 \mathrm{~mm}(4 \mathrm{inch} \times 10 \mathrm{inch}$ ) rectangular exit, and Boot $\mathrm{B}$ a $90 \mathrm{~mm} \times 250 \mathrm{~mm}(3.5 \mathrm{inch} \times 10 \mathrm{inch})$ exit. Illustrations of the boots are shown in Figure 2.

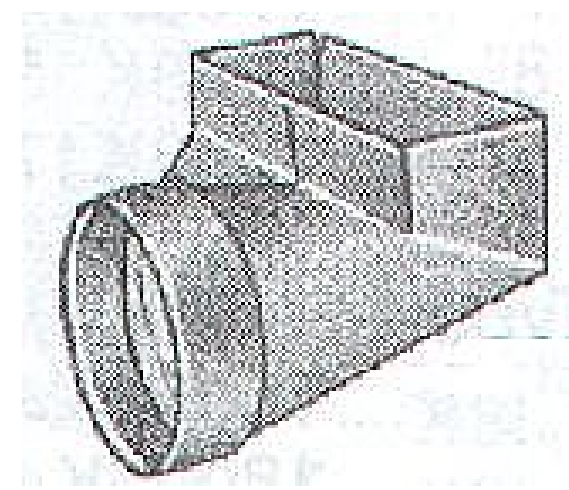

Boot A

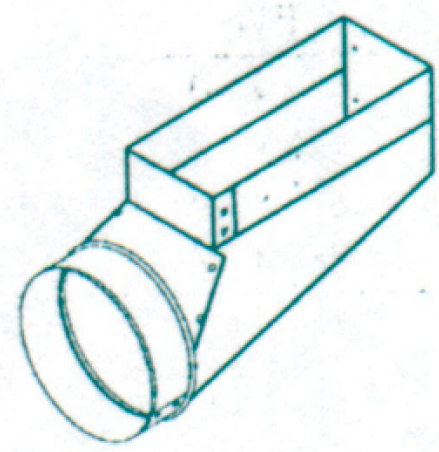

Boot B

Figure 2. Duct boots used in flowhood test apparatus

Two of the registers used in the laboratory tests are shown in Figure 3 . The $100 \mathrm{~mm} \times 250 \mathrm{~mm}(4 \mathrm{inch} \times 10$ inch) one-way-throw register was tested with a "full open" setting and also with the damper blades partially closed (parallel with the outlet fins). The larger square $350 \mathrm{~mm} \times 350 \mathrm{~mm}(13.75 \mathrm{x} 13.75 \mathrm{inch})$ four-way-throw register was tested without a boot. Instead, this register was fastened to a large plenum connected to the discharge end of the test duct system. This grille pattern on this square register induced swirl into the flow. A second square register (not shown) had vanes pointing in the opposite direction to those in Figure 3 to induce swirl of the opposite rotation. The registers were attached to the supporting test surface with masking tape to reduce any edge leakage effects. 

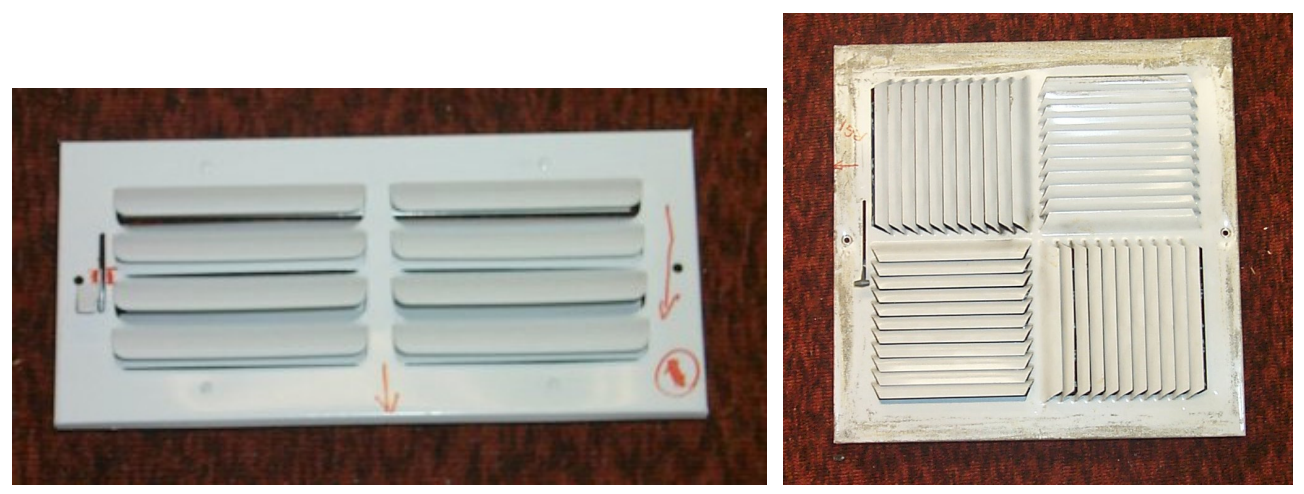

Figure 3. Examples of registers used in flow hood test apparatus

Each flow capture hood was tested at three locations relative to the register: center, corner, and edge. Figure 4 shows the flowhood outlines that were used for registration purposes. These registration marks ensured that the flowhoods were all tested in the same positions relative to the grille.

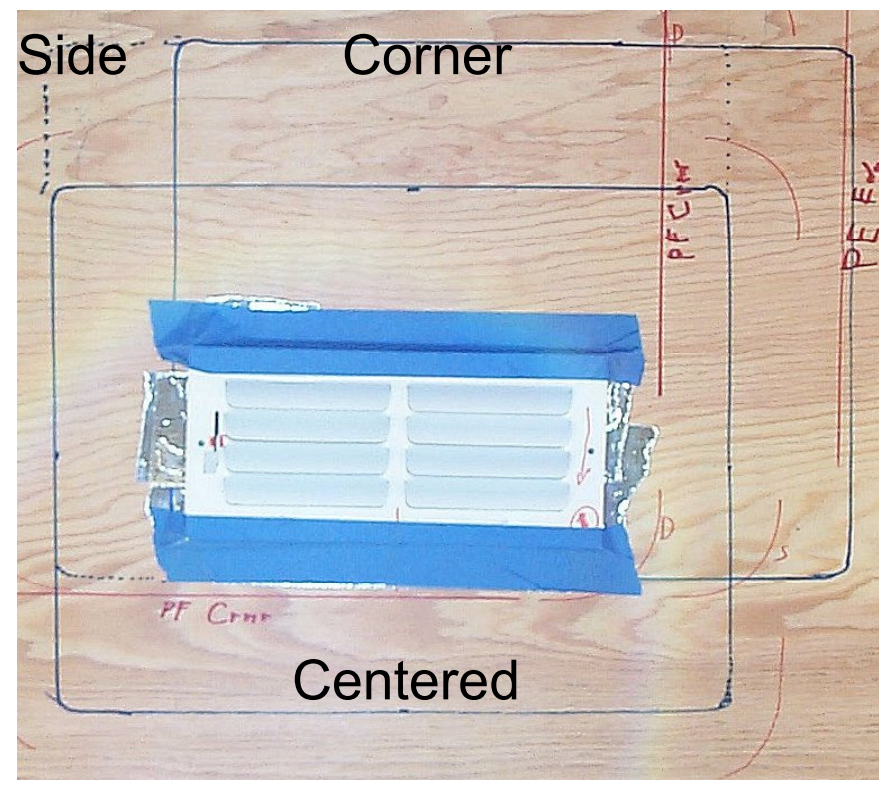

Figure 4: Three flow capture hood positions relative to the register grille

\section{Laboratory test results}

Each flow hood was tested over a range of flows, register type, damper setting, boot type, and register placement. Table 3 summarizes the results of all the tests. The fractional errors are the average of the individual fractional errors for each measurement and not the average error divided by the average flow rate. The average error is an estimate of the bias in the flow hood. The absolute errors do not let positive and negative errors cancel out and are a better indicator of the uncertainty in an individual register measurement. The Reference active flowhood is clearly better than the other passive flow hoods. For return measurements, only Flow Hood 11 was evaluated and it had unacceptably large errors of $30 \%$. 


\begin{tabular}{|c|c|c|c|}
\hline Table 3. Summary of Laboratory Test Results for Supply and Return Flows \\
\hline \hline Hood ID & Average Difference & RMS Difference & Number of Tests \\
\hline \hline \multicolumn{2}{|c|}{ Supplies } & \\
\hline $\begin{array}{c}\text { Reference Active } \\
\text { Hood } 7\end{array}$ & $-1.5 \%(-3 \mathrm{cfm})$ & $2.5 \%(5 \mathrm{cfm})$ & 87 \\
\hline Hood 1 & $8.5 \%(10 \mathrm{cfm})$ & $18 \%(25 \mathrm{cfm})$ & 75 \\
\hline Hood 11 & $-14.5 \%(-18 \mathrm{cfm})$ & $20.5 \%(25 \mathrm{cfm})$ & 43 \\
\hline Hood 12 & $-8.5 \%(-8 \mathrm{cfm})$ & $21 \%(28 \mathrm{cfm})$ & 90 \\
\hline Hood 13 & $-17.5 \%(-19 \mathrm{cfm})$ & $27 \%(36 \mathrm{cfm})$ & 74 \\
\hline \hline \multicolumn{2}{|c|}{ Return } & 9 \\
\hline \hline $\begin{array}{c}\text { Reference Active } \\
\text { Hood 7 }\end{array}$ & $2.5 \%(25 \mathrm{cfm})$ & $3.5 \%(38 \mathrm{cfm})$ & 3 \\
\hline Hood 11 & $33 \%(488 \mathrm{cfm})$ & $33 \%(511 \mathrm{cfm})$ & \\
\hline
\end{tabular}

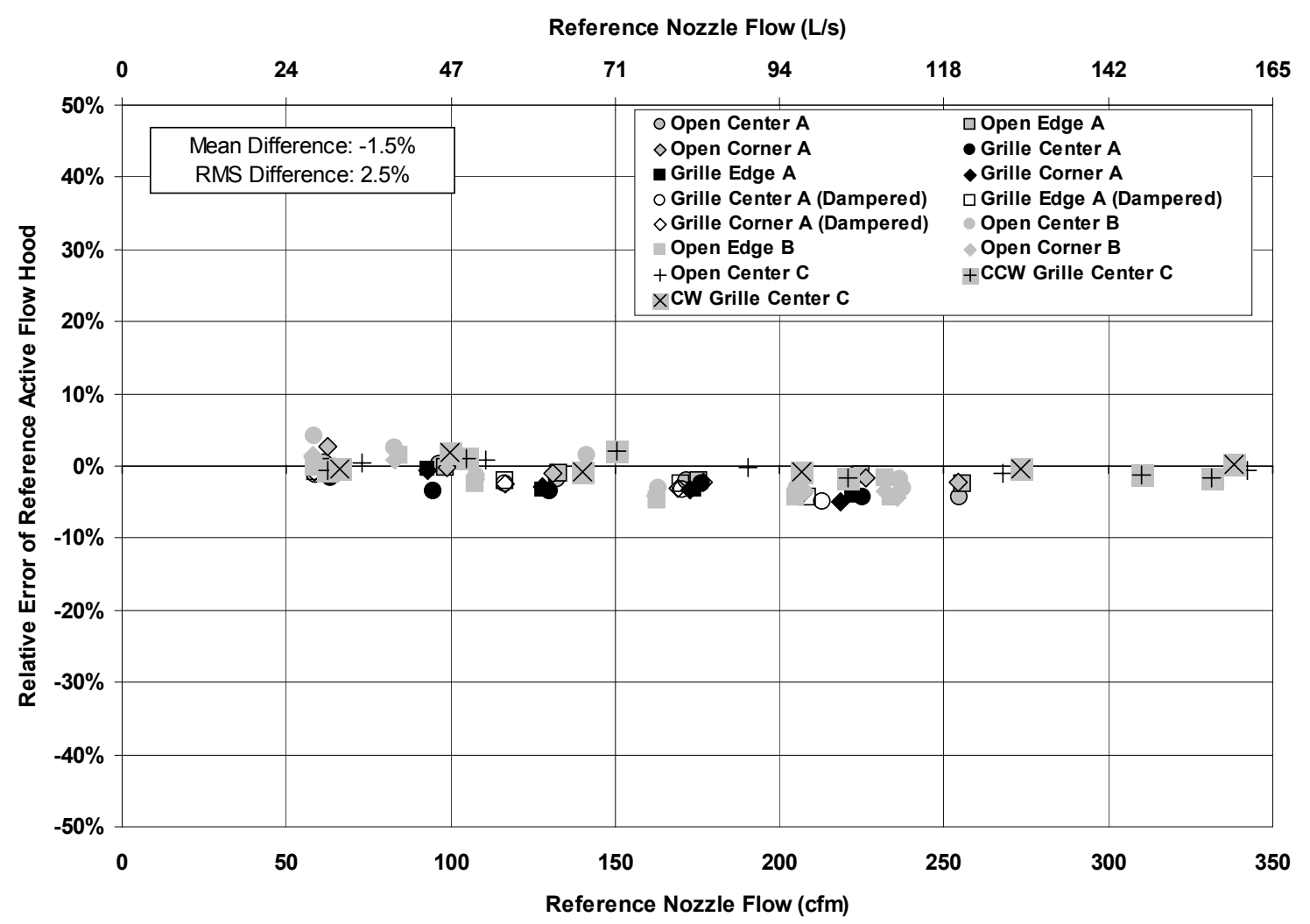

Figure 5. Reference Active flow hood laboratory test results

In Figures 5 through 9, the legend differentiates between the test configurations. OPEN/GRILLE is for tests that either have the grille in place (GRILLE) or no grille and just the open end of the boot (OPEN). Corner/Edge/Center refer to location of the register relative to the flow capture hood as shown in Figure 4. The A/B designation refers to the boots shown in Figure 2. The term "dampered" in parentheses means that the damper in grille was partially 
closed. Lastly, the $\mathrm{CW} / \mathrm{CCW}$ designation refers to the use of a square grille (an example is shown in Figure 4) that introduces swirl in either the Clock-Wise (CW) or Counter-Clock-Wise (CCW) sense. Figure 5 shows how the reference active flowhood is insensitive to the entering flow. The reference active flow hood had all its results fall into a narrow band - with a small negative bias.

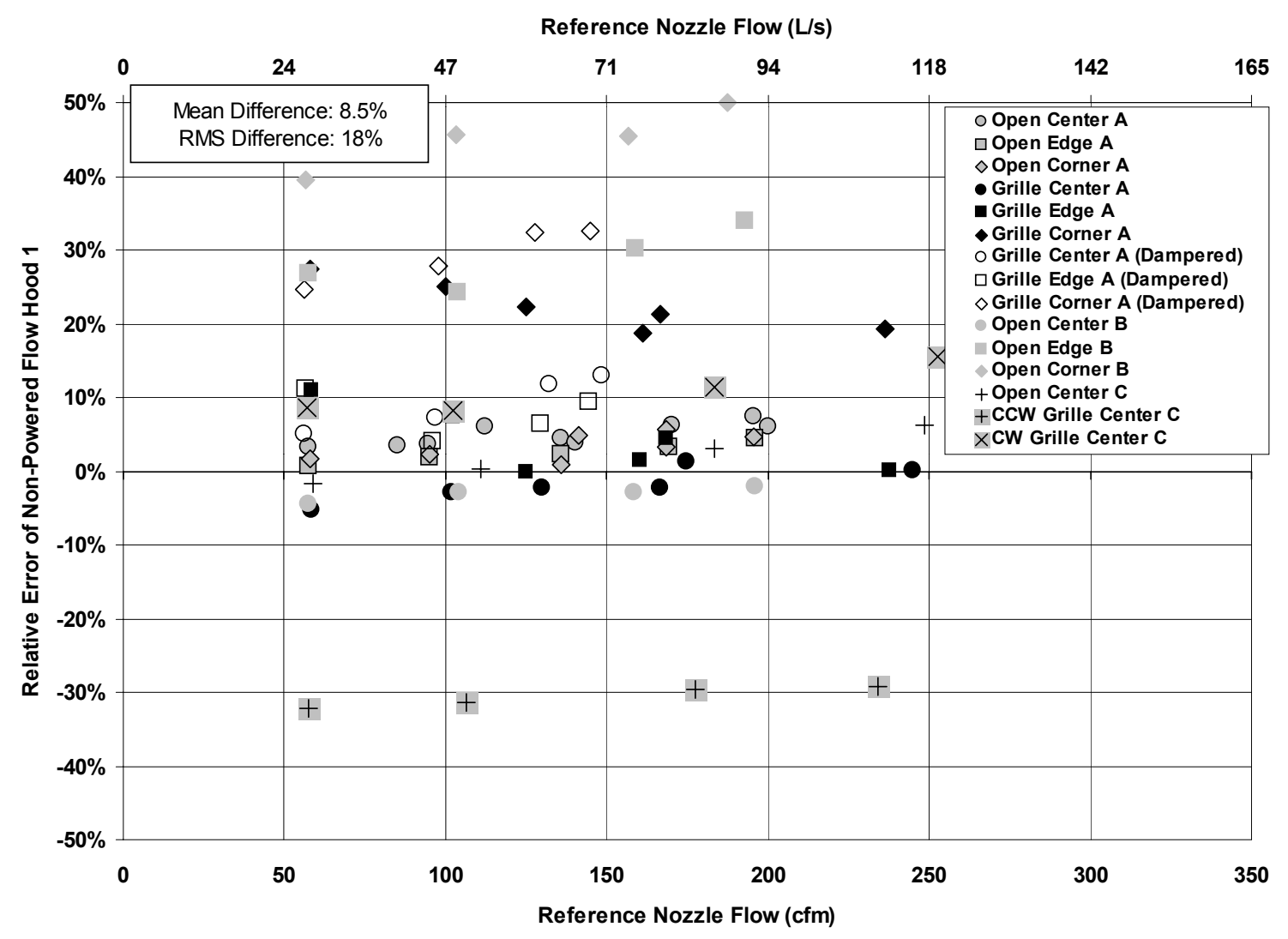

Figure 6. Flow hood one (propeller) laboratory test results

Figure 6 shows that flow hood one (the propeller flow hood) has considerable variation with inlet flow conditions. It is sensitive to swirl in the entering flow and centering of the register in the flow capture section. The CW swirl is in the same direction as propeller rotation and results in the propeller spinning too fast and produces an over estimate (by an average of 11\%) of the flow. Conversely, the CCW swirl acts in opposition to propeller rotation and the flow is underestimated by an average of $30 \%$. The effects of damper position are significant with the dampered results (for Grille center boot A) are 11\% higher on average and have about three times the RMS error than damper fully open. In field applications where occupants have set dampers to control airflow (and do not want them changed) this means that the flow hood errors change from register to register by greater than the acceptable uncertainty for ensuring room load and comfort requirements are met. Moving the flow hood around over the register changes the relative error by about $25 \%$, with placement towards the giving the greatest sensitivity. Because the range of movement of this flow hood is small (arrange of only about $100 \mathrm{~mm}$ (4 inches)) due to its small dimensions, this sensitivity to placement means that placement must be known to within a few $\mathrm{mm}$ which would be difficult to achieve in field testing.

The overall RMS error of $18 \%$ includes the complete range of error sources tested in the laboratory experiments. If detailed information regarding the system to be tested is known then an error estimate can be made based on a more limited set of data. For each set of data with the same register set-up, the majority of the errors are biases that are almost the same at each flow measurement. This means that biases will be generated when summing individual register flows to determine total supply or return flows. For example the Grille Centered Boot A Dampered results (that would be typical of careful placement over a residential register) are biased high by an average of $9 \%$ with an RMS error of $10 \%$. Therefore summing the flows out of many registers of this type in a house would result in an 
overprediction of total register flow by $9 \%$. This makes this flow hood unacceptable for determining total flow for duct leakage estimates and individual flows for ensuring room load and comfort requirements are met even if we restrict the analysis to a subset of the laboratory tests. If all tests are included (because the register type, damper position, boot type and centering are not easily accounted for in field testing) the 18\% RMS uncertainty indicates that this flow hood is unsuitable for room load/comfort requirements, system flow imbalances, air handler flow and duct leakage estimates based on the accuracy criteria in Table 1.

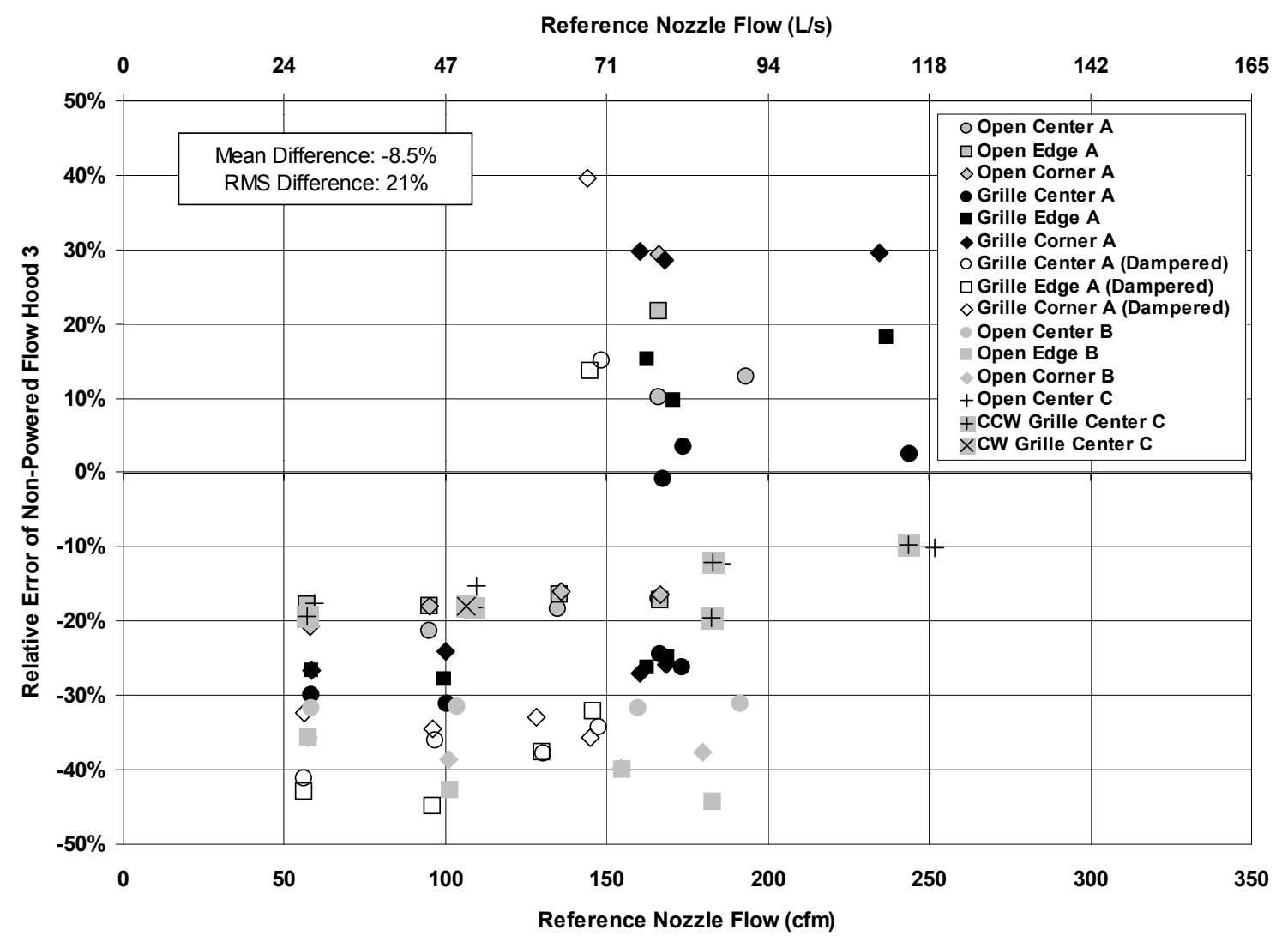

Figure 7. Standard flow hood 12 laboratory test results

Figures 7 and 8 show the laboratory test results for the standard flow hoods. They show a greater sensitivity (higher RMS errors) to inlet flow conditions than flow Hood 1. For the typical application of these flow hoods, with flows below $70 \mathrm{l} / \mathrm{s}(150 \mathrm{cfm})$ there are consistent negative biases of 25 to $30 \%$. Hood 12 only has acceptable performance for identifying large leaks/disconnected ducts and flows for room-to-room pressure balances. For other applications the errors are larger than the criteria set in Table 1. Hood 13 is worse than Hood 12 and only has acceptable performance for finding large leaks or disconnected ducts. Hoods 12 and 13 each have an operable vent intended to reduce backpressure effects at higher flow rates. These flow hoods were operated with the vent open for flows above $70 \mathrm{l} / \mathrm{s}(150 \mathrm{cfm})$, as recommended by the manufacturer. For flows above $70 \mathrm{l} / \mathrm{s}(150 \mathrm{cfm})$, the errors in flows and scatter increase substantially. To determine if this behavior is due to vent position, the vents were opened at lower flows and closed at higher flows, contrary to the manufacturer's recommendation. Field trials have indicated that such an error in operation can readily occur. Closing the vent for flows above $70 \mathrm{l} / \mathrm{s}(150 \mathrm{cfm})$ or opening the vent for flows below $70 \mathrm{l} / \mathrm{s}(150 \mathrm{cfm})$ generally did not reduce error and in some cases caused the error to reverse sign. That is, a positive error became a negative error of similar magnitude, and vice versa. In several cases, the error remained about the same regardless of vent position. 


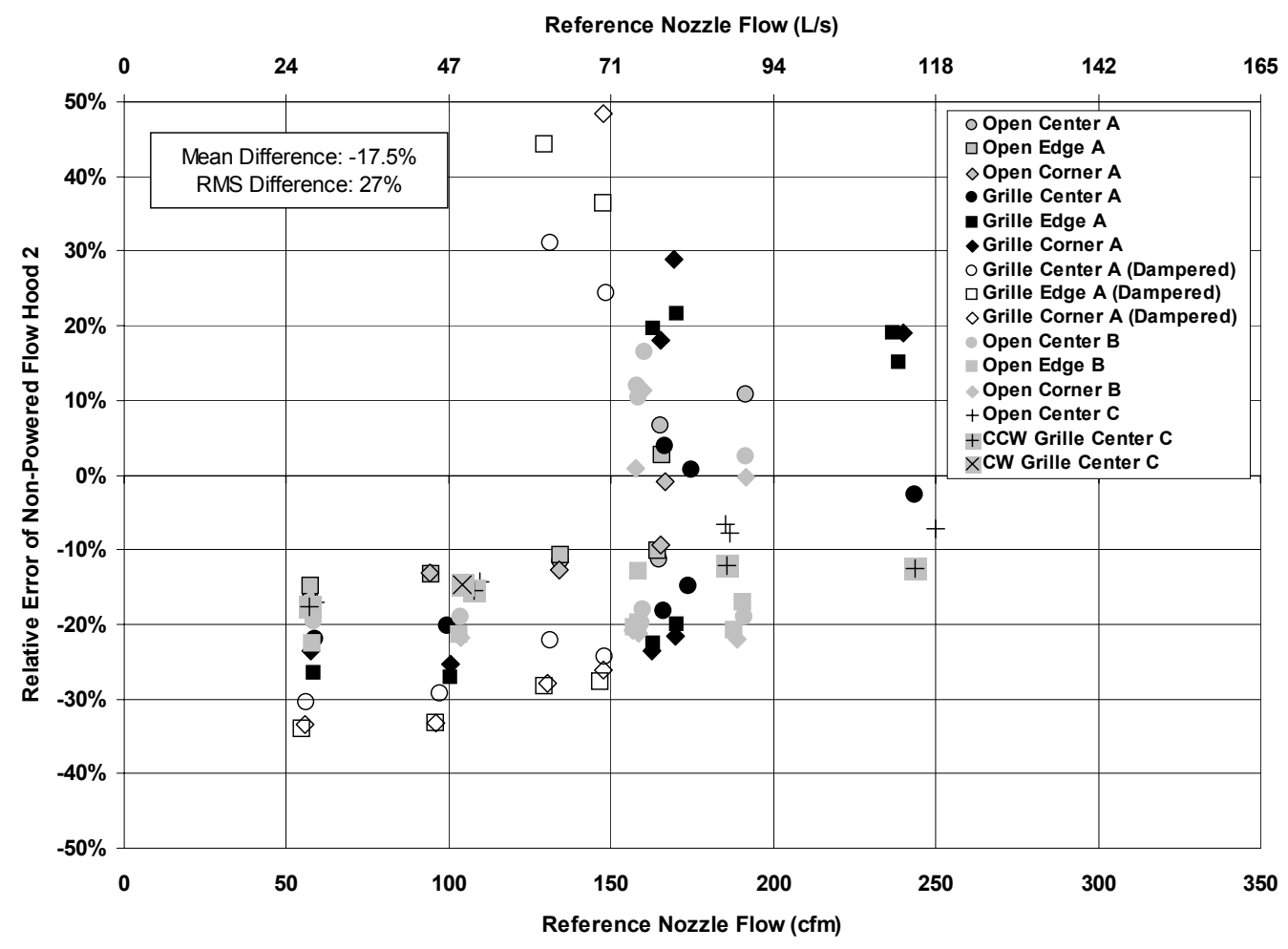

Figure 8. Standard flow hood 13 laboratory test results

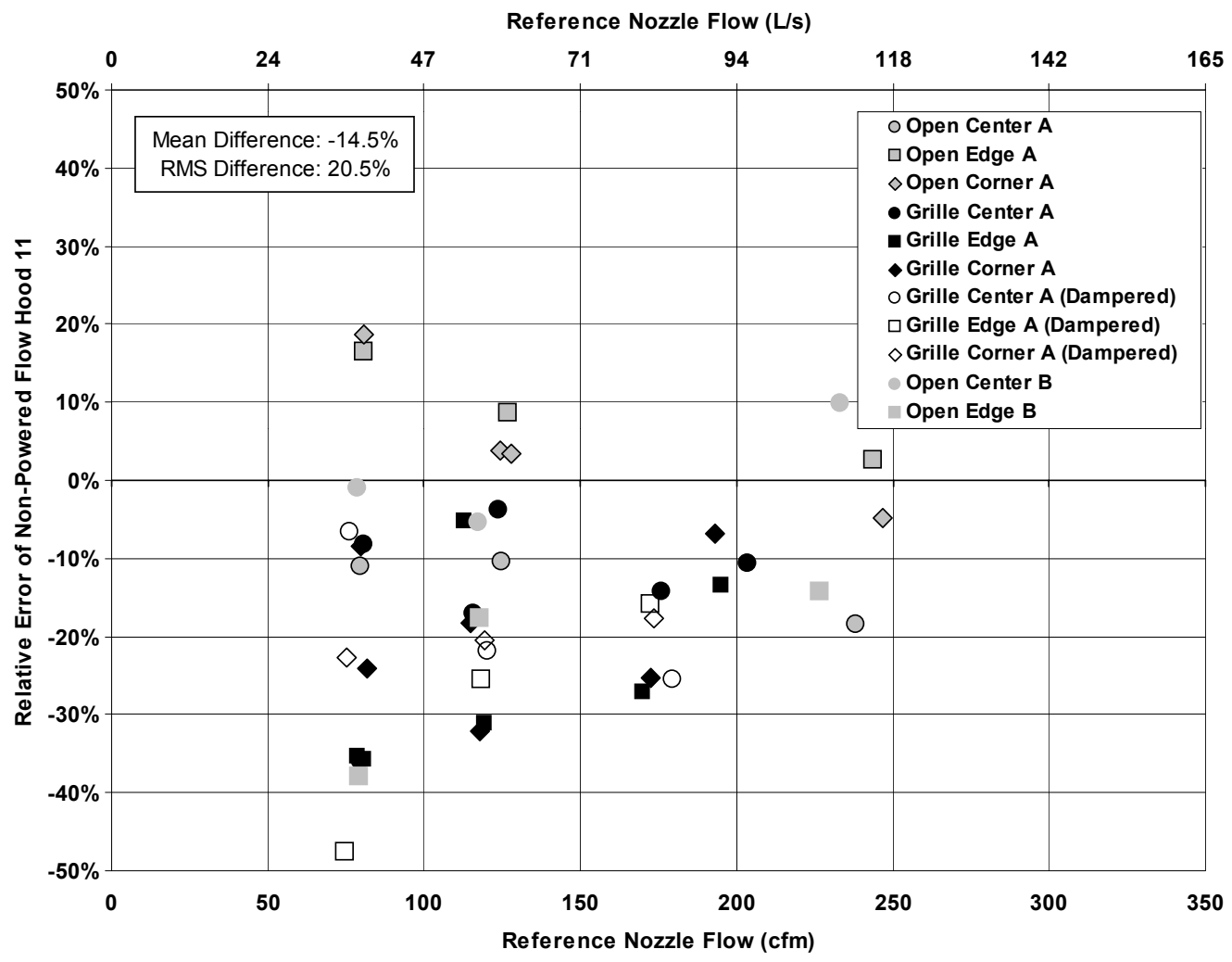

Figure 9. Prototype Hood 11 Laboratory Test Results for Supply Airflows 
Figure 9 shows the laboratory test results for the prototype flow hood (Hood 11). Its errors are less than those for the conventional hoods (Hoods 12 and 13), but greater than those for the propeller hood (Hood 1). These results indicate that the flows measured with Hood 11 are consistently low (14.5\% on average), with few exceptions. The large RMS and mean errors mean that this flow hood is only acceptable for identifying large leaks/disconnected ducts and flows that might result in significant room-to-room pressure imbalances, and it has too much error for other applications listed in Table 1.

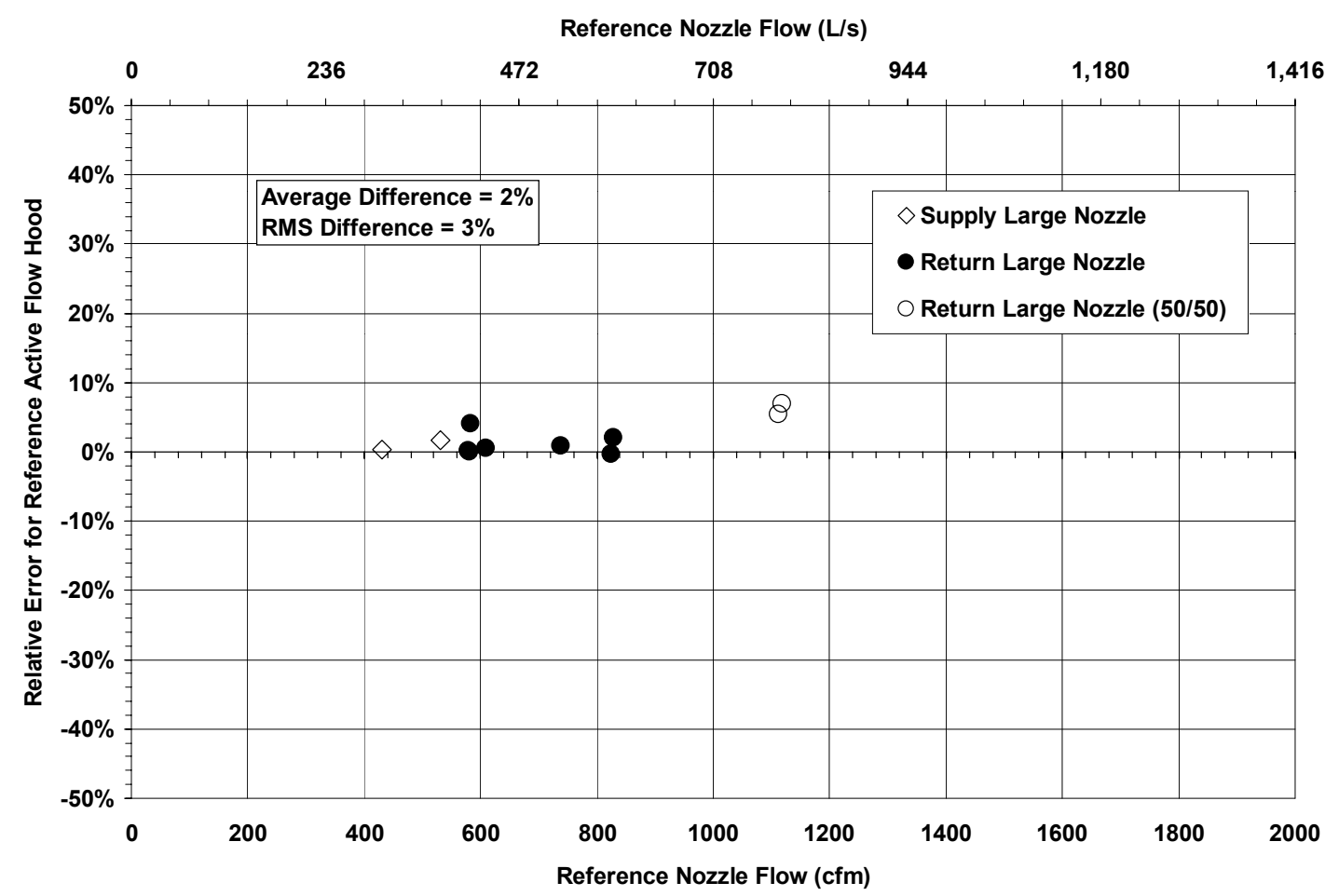

\section{Figure 10. Laboratory Test Results for High Supply and Return Airflows Measured with Reference Active Flow Hood}

The laboratory test facility was used to examine higher flows than usually are obtained in residential systems and to examine return flows, using the Reference active flow hood (Hood 7) and the prototype flow hood (Hood 11). In some cases, larger flows were measured by dividing the discharge or inlet opening into halves (denoted as " $50 / 50$ "). Figure 10 shows that the reference active flow hood is also good at measuring the higher flow rates and return flows. The limitation of this device is that the maximum measurable flow rate with the plastic flexible duct mounted between the flow meter and the capture hood is about $425 \mathrm{l} / \mathrm{s}(900 \mathrm{cfm})$. Figure 11 shows significant positive biases (overestimates of about 33\%) for Flow Hood 11 when measuring the larger supply flows and the return flows. The biases are unlikely due to register geometry, because register geometry effects are all "downstream" of the measurement and should have little effect. Instead, the consistency of the biases indicates they may be due to a calibration error. 


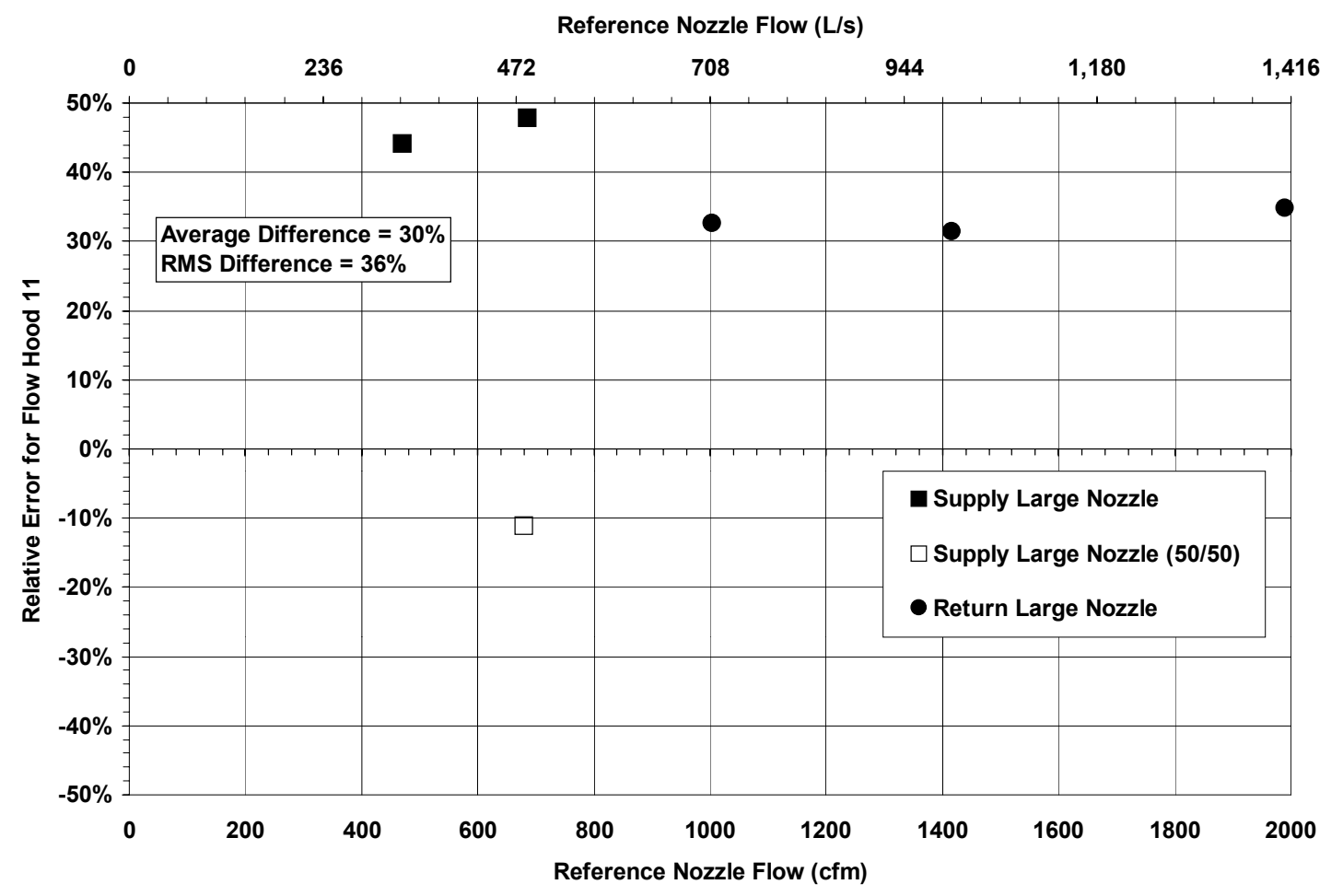

Figure 11. Laboratory Test Results for Supply and Return Airflows Measured with Prototype Flow Hood 11

\section{Conclusions from laboratory testing}

The key conclusion from these laboratory tests is the that active flowhood is very good for measuring register flows because it is not sensitive to incoming flow conditions, therefore it can be used as a reference test method when studying the following field tests. All the other flow hoods exhibit large errors for different configurations of flow entry into the flow hood and are sensitive to register placement. This means that users of these flow hoods need to be very careful when placing hoods over registers and in many cases, where registers are placed near the intersections of walls, floors or ceilings (or in kicker panels, etc.) the measurement errors can become extreme. Comparing the laboratory results to the criteria presented in Table 1 shows that only the reference active flow hood can be used in all applications. None of the other hoods have good enough results to be used to estimate duct leakage, air handler flow, overall system flow imbalances or individual register flows for load and thermal comfort. The applications that require less accuracy (finding big leaks/disconnected ducts and estimating room-to-room pressure imbalances) can be performed by most of the flow hoods. The provision made by some manufacturers to change the flow resistance of the flow meter by opening or closing vents was not found to offer any advantages in improved accuracy.

\section{Calibration versus Application}

This laboratory study shows that commercially available flow hoods are not accurate enough to be used to evaluate air handler flows, duct leakage or individual register measurements for room load and comfort evaluation. The measurement uncertainties arise from poor calibrations and the sensitivity of exiting flow hoods to non-uniformity of flows entering the device. The errors are usually large - about $25 \%$ of measured flow, which is unacceptably high for most applications. Active flow hoods have flow measurement devices that are insensitive to the entering air flow pattern. The results show that they are clearly superior to all commercially available flow hoods and it is recommended that only active flow hoods be used to measure register flows.

It should be noted that the laboratory tests did not include a significant source of measurement uncertainty: insertion losses. Insertion losses are those uncertainties that occur because the added flow resistance of the flow hood reduces the air flow through the register it is placed over. These insertion losses can be of greater significance in residential 
system due to low system operating pressures and short branches near registers that drive the flow out of the neighboring register when one of then is covered. The magnitude of this reduction depends on the flow resistance of the duct branch the register is connected to relative to the added flow resistance of the flow hood. The insertion losses are greater if there is a branch in the duct system just before the register. The placement of the flow hood over the register then significantly increases its flow resistance and decreases its flow and will divert much of this flow to the unmeasured register on the other part of the branch. These insertion losses are reduced by using an active flow hood. Current investigations are under way to evaluate the insertion losses of flow hoods on a full scale laboratory duct system. An attempt is made to account for insertion losses within the calibration of many flow hoods. However, this calibrating out of insertion losses only works for a narrow range of cases because the effect of insertion loss varies by a large magnitude depending on the specific geometry of the duct system and register being tested. In the following field studies the flow hoods are compared to the reference active flow hood that attempts to eliminate these insertion losses by actively removing the flow resistance of the flow hood.

As with other instrumentation, flow hoods are susceptible to large errors in field applications that are not apparent in manufacturers' accuracy specifications. Flow hoods are calibrated in a fixed position with uniform flow, resulting in typical accuracy specifications of about $\pm 3 \%$. Instruction manuals for flow hoods often warn of the possibility of errors due to the airflow pattern from a register differing from the airflow pattern during calibration (e.g. Alnor 1998). However, no estimates of the magnitude of error are given. The field and laboratory tests performed for this report show that the change in airflow pattern between calibration and application creates large flow measurement errors.

ASHRAE Standard 111 (ASHRAE 1988) also discusses flow hood accuracy issues. For example, Section 8.6.4.4 states: "System Effects: Perhaps the most important result of these tests has been to demonstrate that errors as great as $15 \%$ to $30 \%$ may be caused by neglecting the effect of approach conditions.", which agrees closely with the laboratory testing reported in this study. ASHRAE Standard 111 indicates in Section 8.6.5 that one should "...consider most diffuser measurement as not reliable for certifiable accuracy". Current testing and balancing reporting procedures do not emphasize these issues.

Manufacturer's instructions and ASHRAE Standard 111 also discuss the use of pitot-tube traverses to field calibrate the flow hood to account for the problems discussed above. However, this is not a practical solution because:

- In residential systems, there will rarely be duct access so that a traverse can be performed.

- Residential ducts are often made from flexible plastic duct that cannot be used for pitot-tube insertion and mounting (unlike sheet metal ducts).

- Almost no residential duct system has a long enough uninterrupted flow to meet the requirements for an accurate pitot-tube traverse.

- Almost all registers in a residential system have unique duct runs (in terms of fittings, duct length, and layout) and a traverse would be required for every register - obviating the need for a flow hood.

There are still some issues peculiar to residential systems that make register flow measurements particularly difficult. For example, toe kick registers are difficult to access and require some sort of flow capture apparatus to be constructed. In practice, this is usually accomplished by assembling a flow capture system from cardboard that is specifically cut to fit on the toe-kick. There is no other simple method of dealing with this register location and others like it.

\section{Field study one}

Preliminary investigations of flow hood performance in residences were based on a field study. Eight flow hoods were used in a new single story house in Sacramento CA (some of these results reported previously in Walker et al. 1999). The two active flow hoods were operated in two modes to determine sensitivity to the hood pressure used in the pressure matching measurement. The laboratory tests presented earlier established that active hood 7 has the best accuracy and can be used as the reference case for field measurements. Table 4 summarizes the individual register measurements for each of these flow hoods by comparing them to the reference active flowhood. The house had nine supply registers and a single return. The following discussion will concentrate on the supply measurements because none of these flow hoods was large enough to cover the large return grille and correctly measure the return flow. The registers were either high on the wall or in the ceiling. All the ducts in this house were in the attic. 
These results show that some flow hoods $(4,5$ and 6$)$ can give substantially different results from the others. In particular, Hoods 5 and 6 give flows that are much too high, and this is almost certainly a calibration error. These hoods were returned to the manufacturer for recalibrating after these tests, but they were returned with almost identical calibrations. This indicates that the manufacturer of these flowhoods may have a problem in their calibration facility. There are also some significant differences on a register by register basis. The active flowhoods 9 and 10 are almost close enough to the reference to be good enough for individual measurements of register flows used to confirm the room load and comfort requirements are met. The active flow hoods and flow hoods 1 through 3 give good enough results to determine the air handler flow for cooling equipment performance estimation. Also, for this system, the active flow hoods and flow hoods 1 through 3 give good enough results to determine the register flows for use in duct leakage determination. However, the laboratory tests showed that these same flow hoods give results that are highly dependant on register type, geometry and centering of the flowhood and so these good results cannot be extrapolated to all houses. Note that these tests were carried out by experienced researchers and technicians who took a great deal of care and time to make these measurements (e.g., careful flow hood placement to ensure good centering) and represent the best possible results. In particular, the sensitivity to placement would make a big difference to these results if the measurements were performed by poorly trained or inexperienced testers who did not have the luxury of a whole day to perform the tests.

Table 4. Comparison of Supply Register Airflow Measurements

\begin{tabular}{|c|c|c|c|c|c|c|c|c|c|c|}
\hline \multirow[b]{3}{*}{ Register } & \multicolumn{10}{|c|}{ Difference Relative to Reference Active Flow Hood } \\
\hline & \multicolumn{6}{|c|}{ Non-Powered Hoods } & \multicolumn{4}{|c|}{ Active Hoods } \\
\hline & 1 & 2 & 3 & 4 & 5 & 6 & Reference & 8 & 9 & 10 \\
\hline 1 & $-7 \%$ & $-2 \%$ & $-8 \%$ & $4 \%$ & $22 \%$ & $15 \%$ & 197 & $-2 \%$ & $0 \%$ & $3 \%$ \\
\hline 2 & $-1 \%$ & $7 \%$ & $-4 \%$ & $11 \%$ & $37 \%$ & $41 \%$ & 169 & $10 \%$ & $2 \%$ & $4 \%$ \\
\hline 3 & $-2 \%$ & $2 \%$ & $15 \%$ & $2 \%$ & $55 \%$ & $43 \%$ & 239 & $3 \%$ & $2 \%$ & $5 \%$ \\
\hline 4 & $3 \%$ & $7 \%$ & $5 \%$ & $9 \%$ & $54 \%$ & $64 \%$ & 151 & $2 \%$ & $-1 \%$ & $9 \%$ \\
\hline 5 & $-9 \%$ & $-8 \%$ & $7 \%$ & $15 \%$ & $47 \%$ & $63 \%$ & 75 & $0 \%$ & $4 \%$ & $-4 \%$ \\
\hline 6 & $-3 \%$ & $-10 \%$ & $-5 \%$ & $3 \%$ & $57 \%$ & $14 \%$ & 58 & $12 \%$ & $-9 \%$ & $-9 \%$ \\
\hline 7 & $5 \%$ & $-14 \%$ & $-5 \%$ & $4 \%$ & $56 \%$ & $60 \%$ & 98 & $-2 \%$ & $-8 \%$ & $-3 \%$ \\
\hline 8 & $10 \%$ & $-12 \%$ & $8 \%$ & $-12 \%$ & $69 \%$ & $71 \%$ & 49 & $8 \%$ & $-8 \%$ & $-6 \%$ \\
\hline 9 & $16 \%$ & $-2 \%$ & $18 \%$ & $36 \%$ & $98 \%$ & $86 \%$ & 44 & $18 \%$ & $7 \%$ & $5 \%$ \\
\hline \multirow[t]{2}{*}{$\begin{array}{c}\text { All } \\
\text { Registers }\end{array}$} & $-1 \%$ & $-1 \%$ & $3 \%$ & $7 \%$ & $48 \%$ & $45 \%$ & $\begin{array}{c}\text { Average } \\
\text { Difference }\end{array}$ & $4 \%$ & $-1 \%$ & $2 \%$ \\
\hline & $8 \%$ & $8 \%$ & $10 \%$ & $15 \%$ & $58 \%$ & $56 \%$ & $\begin{array}{c}\text { RMS } \\
\text { Difference }\end{array}$ & $9 \%$ & $6 \%$ & $6 \%$ \\
\hline
\end{tabular}

\section{Pressure balancing}

Comparing the reference flow hood that uses a reference pressure approximating the total air pressure to Flow Hood 8 using an approximation to static pressure shows that the static pressure balancing results in consistently ( 7 out of 9 registers) higher flow measurements. However, the differences are quite small - less than the specified flow measurement uncertainty ( $\pm 3 \%$ of flow) for 5 of the 9 registers. Further tests are planned to investigate this effect. Comparing the Flow Hood 9 and Flow Hood 10 results shows that the static pressure measurement location is not critical. The differences between the two tests are less than the flow meter measurement uncertainty ( $\pm 3 \%$ of flow) for all but two of the registers. 


\section{Comparing return measurements}

Due to limited capacity not all of the flow hoods had the capability to measure the return flows. Table 5 compares the results for the six flow hoods that were used to measure the return flow, with relative differences compared to the reference active hood. These results show good agreement between hoods 4 through 8 , but hood 3 gave results that were too low. The improved results for hoods 5 and 6 are the result of the hood using a different calibration for supply and return flows. For hood 3, the return flow measurement was at the upper limit of its measurement range. This flow hood added significant flow restriction to the return, resulting in a lower flow through the register and flow hood. Hoods 5, 6 and 8 gave return flow measurements that were good enough to be used in a duct leakage calculation (if there is no uncertainty in the air handler flow measurement). Hood 4 is not quite good enough to meet the performance criteria for measuring leakage but it could be used to determine the air flow for equipment performance evaluation (assuming no uncertainty in the return duct leakage).

\begin{tabular}{|cccc|cc|}
\hline \multicolumn{5}{|c|}{ Table 5: Comparison of Return Grille Airflow } \\
Measurements \\
\hline \multicolumn{5}{|c|}{ Return Airflow (cfm) versus Hood ID } \\
\hline Non-Powered Hoods & \multicolumn{2}{c|}{ Active Hoods } \\
\hline Hood 3 & Hood 4 & Hood 5 & Hood 6 & $\begin{array}{l}\text { Reference } \\
\text { (Hood 7) }\end{array}$ & Hood 8 \\
\hline 860 & 995 & 1,028 & 1,055 & 1,037 & 1,057 \\
\hline-177 & -42 & -9 & 18 & $\begin{array}{c}\text { Flow } \\
\text { Difference } \\
\text { (cfm) }\end{array}$ \\
\hline$-17 \%$ & $-4 \%$ & $-1 \%$ & $2 \%$ & $\begin{array}{c}\text { Fractional } \\
\text { Flow } \\
\text { Difference }\end{array}$ \\
\hline
\end{tabular}

\section{Field Study Two}

In a more recent field study two flowhoods were compared in four houses. The two flowhoods were the Reference active flow hood and the prototype flow hood 11 .

Supply Flow Test Results: Figure 12 shows the results of this comparison for all the supply registers in the four test houses. These results show that the flows measured with Hood 11 are consistently low, with few exceptions (as was also found in the laboratory tests). The mean difference of $-16.5 \%$ (about $-7 \mathrm{l} / \mathrm{s}$ or $-15 \mathrm{cfm}$ ) and the RMS difference is $22 \%$ (about $9 \mathrm{l} / \mathrm{s}$ or $19 \mathrm{cfm}$ ), make this flow hood unsuitable for the diagnostics listed in Table 1 except for identifying large leaks and room-to-room pressure imbalances.

Return Flow Test Results: Table 6 compares the return flows that were measured in the four houses. The differences listed are relative to the Reference active flow hood. The results in Table 6 show good agreement in Houses 1 and 2, but poor agreement in the other two houses. Return Grilles 3 through 5 required split measurements. That is because the grilles were larger than the flow hood inlets and only partial sections of the grille could be measured at any one time. Grilles 3 and 4 were each split into thirds; Grille 5 was split into halves. The results shown are the sum of individual measurements. Some of the large errors may be due to the splitting process because it is easy for air flow to bypass the flow hoods. The average difference was an underprediction of $9 \%$ and an RMS difference of $14 \%$. 


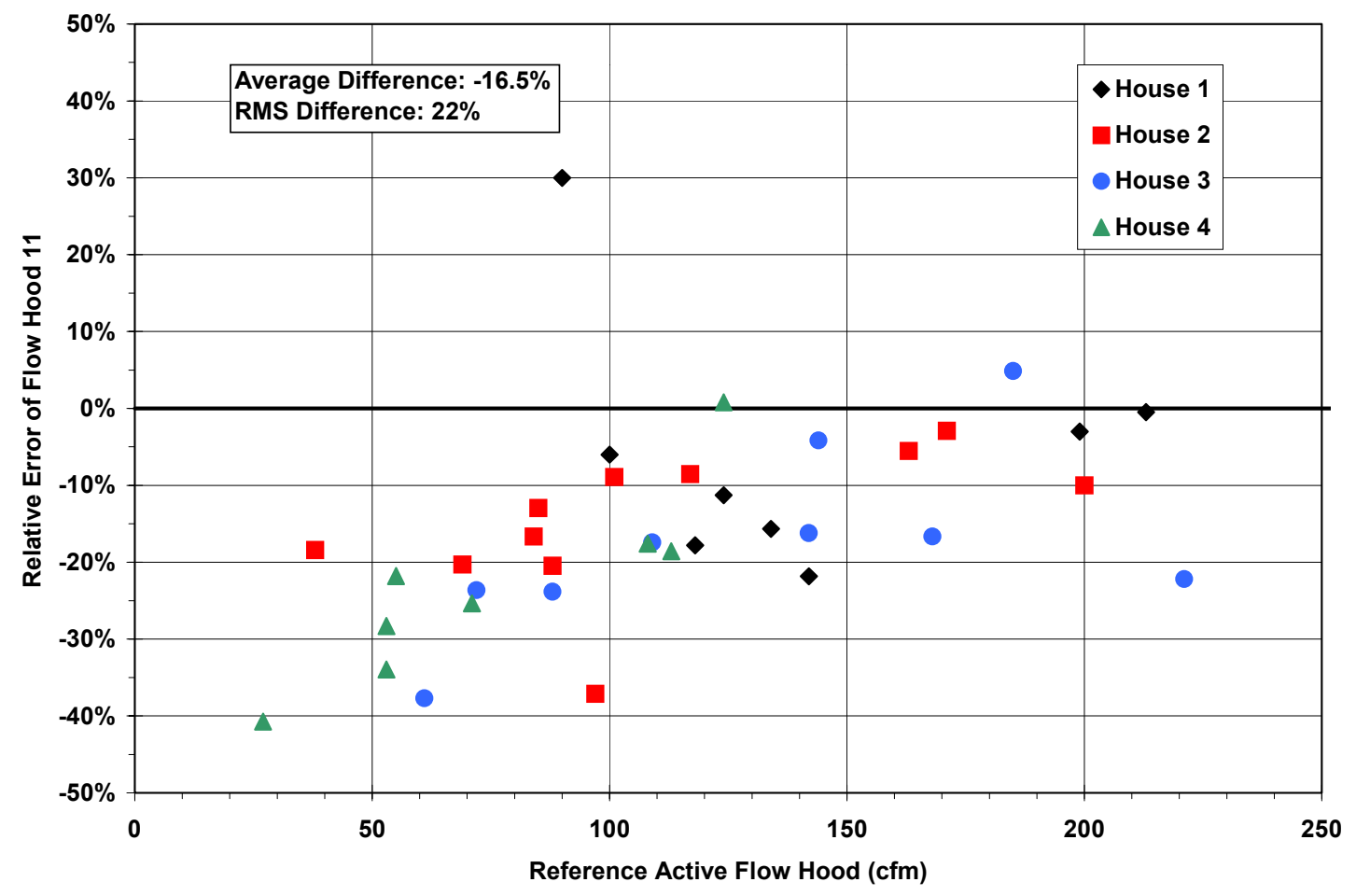

Figure 12. Results of a field test comparison between prototype Flow Hood 11 and the Reference active flow hood for supply registers in four test houses

Table 6: Comparison of 6 Return Grille Airflows Measured in Four Houses using the Reference Active Flow Hood and Hood 11

\begin{tabular}{|c|cc|c|c|}
\hline \multirow{2}{*}{$\begin{array}{c}\text { Return } \\
\text { Grille (House) }\end{array}$} & \multicolumn{3}{|c|}{ Airflow (cfm) } & \multirow{2}{*}{ Fractional } \\
\hline \hline & Reference & $\begin{array}{c}\text { Prototype } \\
\text { Hood 11 }\end{array}$ & $\begin{array}{c}\text { Flow } \\
\text { Difference }\end{array}$ & Difference \\
\hline \hline $1(1)$ & 108 & 107 & -1 & $-1 \%$ \\
\hline $2(1)$ & 170 & 176 & 6 & $4 \%$ \\
\hline $3(2)$ & 1,166 & 1,153 & -13 & $-1 \%$ \\
\hline $4(3)$ & 1,416 & 1,080 & -336 & $-24 \%$ \\
\hline $5(4)$ & 428 & 325 & -103 & $-24 \%$ \\
\hline $6(4)$ & 112 & 104 & -8 & $-7 \%$ \\
\hline
\end{tabular}




\section{Key Findings}

Extensive laboratory tests and several field tests have shown that commercially available standard flow hoods do not meet the accuracy criteria for many of the diagnostics that flow hoods are often used for. Their RMS errors are typically in the $20 \%$ to $30 \%$ range compared to accuracies of $10 \%$ or better required for most distribution system diagnostics. In particular, they are inadequate for use in estimating duct leakage, air handler flow and individual register flows for room load and comfort. Their measurement accuracy is too poor for individual registers and also over the sum of many registers. The laboratory results for the reference active flow hood show an RMS error of only $2 \%$. Comparing this result to the criteria presented in Table 1 shows that this active flow hood can be used in all applications. The applications that require less accuracy (finding big leaks/disconnected ducts and estimating room-to-room pressure imbalances) can be performed by most of the flow hoods. The provision made by some manufacturers to change the flow resistance of the flow meter by opening or closing vents was not found to offer any advantages in improved accuracy.

The flowhood errors are mostly due to non-uniformity of incoming flow from typical residential registers. The nonuniformity has two sources: the duct system itself (including the register grille) and the use of the flowhood. The duct system contributions include the effects of the flow pattern generated by the grille, the changes in flow pattern because of the use of register dampers, swirl in the flow (either generated by the grille or upstream ducts), and the boot entry type. The positioning of the flowhood over the register was also found to be critical - the flowhood needs to be well centered for best results. Because the results are very sensitive to positioning (the biggest errors ( $\pm 40 \%)$ were the result of poor centering), this is a key issue in the field application of flowhoods. In field applications, the user often has little choice over flow hood placement due to registers being located near the intersection of walls, floors and ceilings (or other obstructions). In addition, the great care required to adequately center flow hoods means that the testing requires more extensive operator training and greater time to carry out.

Because the laboratory tests were performed on a single branch system with no leaks, they did not estimate the effects of insertion losses, i.e., the reduction in flow due to the added flow resistance of the flowmeter. This added uncertainty will be estimated in future laboratory experiments on a full scale duct system.

The field test results are less conclusive due to the less controlled nature of field experiments. The field tests showed that (for the systems tested) some flow hoods gave acceptable results and others did not. For example, the biases for the sum of all register flows were less than 5\% compared to the active reference for six of the tested flow hoods showing that the results in this case would be good enough to estimate the efficiency changes due to reduced air flows (but not for duct leakage). The higher RMS errors indicate that even the flow hoods with good estimates of the total flow are not accurate enough to meet the $\pm 5 \%$ specification for determining if individual room load and comfort requirements are met. The second field study that compared only two flow hoods, illustrated how flowhood performance can depend on the particular system being tested (different register grilles, boots and upstream duct work ). All the field tests were conducted by experienced researchers who took as much time as necessary to achieve the best possible results for each flow hood (e.g., taking particular care to center the flow hoods). It is expected that the errors reported for the field tests are lower than those from a typical HVAC diagnostic. A field test survey would be required to estimate this additional "operator error".

\section{Recommendations}

Active flow hoods should be used to measure distribution system airflows if the measurements are to be used in estimating duct leakage, air handler flow and individual register flows for room load and comfort.

Because the active flow hood is the most accurate hood, it can be used as a standard hood in field evaluations of other flow hoods.

A new flow hood measurement standard should be developed to address how flow hoods are operated in the field. This standard should have some standard register sizes, types, and placements that would cover most common geometries found in residential systems. The laboratory tests used for this report are a prototype for this standard test procedure. Possible agencies for development of this standard are ASHRAE and ASTM. 


\section{Acknowledgements}

The authors would like to thank the EPB staff and students who contributed to the field and laboratory flow hood tests and provided thoughtful guidance for this report: Duo Wang, Bass Abushakra, Brian Smith, Woody Delp, Jennifer McWlliams, Sylvain Masson, and Brian Carrol. In addition, the first field study included contributions from the staff of Davis Energy Group (Marc Hoeschele), The Energy Conservatory (Gary Nelson) and CONSOL (Rob Hammon) and the California Energy Commission.

\section{References}

ALNOR. 1998. LoFlo Balometer ${ }^{\circledR}$ Owners Manual. ALNOR Instrument Company, Skokie, IL.

ASHRAE. 1997. ASHRAE handbook of Fundamentals, Chapter 26. ASHRAE, Atlanta, GA.

ASHRAE. 1998. ASHRAE/ANSI Standard 111-98 Practices for Measurement, Testing, Adjusting and Balancing of Building Heating, Ventilation, Air-Conditioning and Refrigeration Systems. ASHRAE, Atlanta, GA.

California Energy Commission (CEC). 1998. Low-Rise Residential Alternative Calculation Method Approval Manual for 1998 Energy Efficiency Standards for Low-Rise Residential Buildings. California Energy Commission, Sacramento, California.

Choat, E.E. 1999. Resolving Duct Leakage Claims. ASHRAE Journal, March 1999. pp. 49-53. ASHRAE, Atlanta, GA.

Rodriguez, A.G., O’Neal, D.L., Bain, J.A., and Davis, M.A. 1995. The Effect of Refrigerant Charge, Duct Leakage, and Evaporator Air Flow on the High Temperature Performance of Air Conditioners and heat Pumps. Energy Systems Laboratory, Dept. of Mechanical Engineering, Texas Engineering Experiment Station, Texas A\&M University.

Walker, I., Sherman, M., and Siegel, J. 1999. Distribution Effectiveness and Impacts on Equipment Sizing. Lawrence Berkeley National Laboratory, Berkeley, CA. LBNL 43724 